\title{
Detection and quantification of STLV-1 and SFV proviral load in blood and saliva of naturally infected non-human primates
}

\author{
Sandrine Alais ${ }^{1,2,3,4,5}$, Amandine Pasquier ${ }^{1,2,3,4,5,6}$, Jocelyn Turpin ${ }^{1,2,3,4,5}$, Rejane Rua ${ }^{7}$, Antoine Gessain ${ }^{7}$, \\ Romain Lacoste ${ }^{8}$, Renaud Mahieux $1,2,3,4,5^{*}$
}

From 17th International Conference on Human Retroviruses: HTLV and Related Viruses

Trois llets, Martinique. 18-21 June 2015

Simian T Lymphotropic Virus type 1 (STLV-1) and Simian Foamy Virus (SFV) retroviruses infect Old World non-human primates (NHP) and humans. Interhuman transmission has been described for HTLV-1 but not for SFV. SFV infection is asymptomatic in its hosts, while STLV-1 and its human counterpart HTLV- 1 are the etiologic agents of Adult T-cell Leukemia/Lymphoma. Both STLV-1 and SFV can be zoonotically transmitted from NHP to humans through severe bites, thus involving contact between virus-containing saliva in the donor and blood in the recipient. Surprisingly, while the presence of both SFV RNA and DNA has been characterized into the saliva of NHP, neither STLV-1 DNA, nor STLV-1 RNA was quantified. Thus, the goal of our study was to search for STLV-1 provirus in the cells present in the saliva of NHP and then to quantify the proviral load of both viruses. We took advantages of a cohort of 45 papio anubis, naturally infected by STLV-1. We first assessed SFV infection and then potential SFV/STLV-1 co-infections. To this end, we designed semi-nested PCR and qPCR protocols (1) to diagnose infection and (2) to quantify STLV-1 and/or SFV proviral load in peripheral blood cells and in saliva. First, STLV-1 provirus was detected by semi-nested PCR in $8 / 10$ blood samples tested, but only in the saliva of 1/10 NHP who had a high STLV-1 proviral load in peripheral blood cells. SFV DNA was detected by nested-PCR in blood samples from 10/10 baboons and in the saliva of $8 / 10$ animals. A second study performed with 20 animals will be presented. We will show whether a correlation exists between blood and saliva STLV-1/SFV proviral load and whether infection with one retrovirus impacts proviral load of the other. Altogether, our current results suggest that SFV is more frequently present in saliva than STLV-1. This should impact the ability of both viruses to be zoonotically transmitted through bites.

\section{Authors' details}

${ }^{1}$ Equipe Oncogenèse Rétrovirale, International Center for Research in Infectiology, INSERM U1111 - CNRS UMR5308, France. Equipe labellisée "Ligue Nationale Contre le Cancer", International Center for Research in Infectiology, INSERM U1111 - CNRS UMR5308, France. International Center for Research in Infectiology, INSERM U1111 - CNRS UMR5308, France. ${ }^{4}$ Ecole Normale Supérieure de Lyon, Lyon, France. ${ }^{5}$ Université Lyon 1, Lyon, 69364 Cedex 07, France. ${ }^{6}$ Ecole Pratique des Hautes Etudes, Pasteur Institute, Paris, 75724 Cedex 15, France. ${ }^{7}$ Epidémiologie et Physiopathologie des Virus Oncogènes, CNRS UMR 3569, Pasteur Institute, Paris, 75724 Cedex 15, France. ${ }^{8}$ Station de Primatologie-UPS846-CNRS, Rousset sur Arc, 13790, France.

Published: 28 August 2015

\section{doi:10.1186/1742-4690-12-S1-P4}

Cite this article as: Alais et al:: Detection and quantification of STLV-1 and SFV proviral load in blood and saliva of naturally infected non-human primates. Retrovirology 2015 12(Suppl 1):P4

\footnotetext{
* Correspondence: renaud.mahieux@ens-lyon.fr

'Equipe Oncogenèse Rétrovirale, International Center for Research in Infectiology, INSERM U1111 - CNRS UMR5308, France

Full list of author information is available at the end of the article
} 